\title{
Effect of hyperlipidemia on the incidence of cardio-cerebrovascular events in patients with type 2 diabetes
}

\author{
Dabei Fan ${ }^{1 *}{ }^{*}, \mathrm{Li} \mathrm{Li}^{2+}$, Zhizhen $\mathrm{Li}^{1}$, Ying Zhang ${ }^{1}$, Xiaojun $\mathrm{Ma}^{1}$, Lina Wu${ }^{1}$ and Guijun Qin ${ }^{1}$ (B)
}

\begin{abstract}
Background: This study was to explore the effect of hyperlipidemia on the incidence of cardio-cerebrovascular diseases in patients with type 2 diabetes.

Methods: Three hundred ninety five patients with type 2 diabetes in our hospital from January 2012 to January 2016 were followed up with an average of 3.8 years. The incidence of cardio-cerebrovascular diseases between diabetes combined with hyperlipidemia group (195 patients) and diabetes group (200 patients) were made a comparison. Multivariable Cox's proportional hazards regression model was used to analyze the effect of hyperlipidemia on the incidence of cardio-cerebrovascular diseases in patients with type 2 diabetes.
\end{abstract}

Results: Diastolic blood pressure, systolic blood pressure, high-density lipoprotein, low-density lipoprotein, body mass index and hyper-sensitive C-reactive protein were higher in diabetes combined with hyperlipidemia group than in diabetes group $(P<0.05)$. At the end of the follow-up period, all-cause mortality, cardio-cerebrovascular diseases mortality, and the incidence of myocardial infarction, cerebral infarction, cerebral hemorrhage and total cardiovascular events were significantly higher in diabetes combined with hyperlipidemia group than in diabetes group $(P<0.05)$. The analysis results of multivariable Cox's proportional hazards regression model showed that the risks of myocardial infarction and total cardiovascular events in diabetes combined with hyperlipidemia group were respectively 1.54 times $(95 \% \mathrm{Cl} 1.13-2.07)$ and 1.68 times $(95 \% \mathrm{Cl} 1.23-2.24)$ higher than those in diabetes group. Population attributable risk percent of all-cause mortality and total cardiovascular events in patients with type 2 diabetes combined with hyperlipidemia was $9.6 \%$ and $26.8 \%$, respectively.

Conclusions: Hyperlipidemia may promote vascular endothelial injury, increasing the risk of cardio-cerebrovascular diseases in patients with type 2 diabetes. Medical staffs should pay attention to the control of blood lipids in patients with type 2 diabetes to delay the occurrence of cardio-cerebrovascular diseases.

Keywords: Hyperlipidemia, Type 2 diabetes, Cardio-cerebrovascular diseases, Hypertension

\section{Background}

The latest data from the International Diabetes Federation revealed that there were 387 million diabetics worldwide in 2014. In high-income countries, type 2 diabetes accounted for $85 \%$ 95\% of diabetes, which might be higher in middle-income and low-income countries. By the year 2035 the number of diabetic patients is expected to increase by $55 \%$ to 600 million. The burden of

\footnotetext{
* Correspondence: debeifan@sina.com

${ }^{\dagger}$ Equal contributors

'Division of Endocrinology Department of Internal Medicine, The First Affiliated Hospital of Zhengzhou University, Zhengzhou, Henan, China Full list of author information is available at the end of the article
}

diabetes is growing more severe as a result of the increasing number of deaths from diabetes and medical costs [1]. Diabetic patients often combined with metabolic disorders like hypertension, and hyperlipidemia, easily lead to cardio-cerebrovascular diseases like coronary heart disease, which is a risk factor leading to death [2]. Diabetes complications, cardio-cerebrovascular diseases are the common factors that cause the death of patients. According to statistics, more than $75 \%$ of diabetic patients die from cardio-cerebrovascular diseases every year [3]. According to statistics, there are some $30 \%-40 \%$ of diabetic patients in China with hyperlipidemia [4]. 
Hyperlipidemia and diabetes are independent risk factors of cardio-cerebrovascular diseases [5, 6], and the coexistence of the two can increase the risk of cardiocerebrovascular diseases $[7,8]$. An epidemiological survey showed the incidence of acute stroke in patients with high hyper-sensitive C-reactive protein (hs-CRP) level was two times higher than healthy people and myocardial infarction was three times higher [9]. We followed up 395 patients with type 2 diabetes in our hospital from January 2012 to January 2016, and analyzed as follow.

\section{Methods}

\section{Clinical data}

Three hundred ninety five patients with type 2 diabetes in our hospital from January 2012 to January 2016 were divided into diabetes combined with hyperlipidemia group (195 patients) and diabetes group (200 patients). Whether patients have a family history of diabetes were inquired. Inclusion criteria: (1) fasting plasma glucose (FPG) $\geq 7.0 \mathrm{mmol} / \mathrm{L}$; (2) $\mathrm{FPG}<7.0 \mathrm{mmol} / \mathrm{L}$ but patients were previously diagnosed with diabetes and were using hypoglycemic agent [10]. Exclusion criteria: (1) previous history of myocardial infarction; (2) previous history of stroke; (3) refusing to sign an informed consent; (4) incomplete baseline data.

\section{Diagnostic criteria}

Diabetes diagnosis based on the guidelines for the prevention of diabetes in China in 2010 and hypertension diagnosis based on the guidelines for the prevention of hypertension in China in 2011 [11]: systolic blood pressure (SBP) $\geq 140 \mathrm{mmHg}$ and/or diastolic blood pressure $(\mathrm{DBP}) \geq 90 \mathrm{mmHg}(1 \mathrm{mmHg}=0.133 \mathrm{kPa})$, or normal blood pressure but taking anti-hypertensive drugs. Definition of obesity [11]: body mass index (BMI) $\geq 28 \mathrm{~kg} / \mathrm{m}^{2}$. Definition of hyperlipidemia [12]: total cholesterol $\geq 5.72 \mathrm{mmol} / \mathrm{L}$. Definition of smoking history: one or more cigarettes every day, lasting over 1 year. Definition and diagnostic criteria of cardiovascular disease: cardio-cerebrovascular events include fatal and nonfatal cardio-cerebrovascular events. Cardiac events include acute myocardial infarction and sudden cardiac death. Acute myocardial infarction is diagnosed according to the diagnostic criteria developed by the Chinese Medical Association's Cardiovascular Disease Branch [13]. Sudden cardiac death is diagnosed according to the diagnostic criteria of the American College of Cardiology/American Heart Association/European Society of Cardiology Committee in 2006 [14]. Cerebrovascular events including cerebral infarction and cerebral hemorrhage, are diagnosed according to the diagnostic criteria of Cerebrovascular Disease Classification (1995) developed by the Fourth National Conference on Cerebrovascular Disease [15]. Cardiovascular events include heart failure, myocardial infarction, and sudden death. The total cardio-cerebrovascular events include myocardial infarction, cerebral infarction and cerebral hemorrhage. When the total cardio-cerebrovascular events are counted, one event occurring two or more times is recorded only 1 time, ending with the time and event of the first endpoint event.

\section{Follow-up method}

Follow-up period arranged from January 2012 to January 2016. New-onset cardio-cerebrovascular events were collected every three months. First, professional clinicians collected the main cardio-cerebrovascular events records of participants through the Zhengzhou City Medical Insurance Management Center. Subsequently, cardio-cerebrovascular physicians consulted patients' medical records to confirm the occurrence time and type of cardio-cerebrovascular events and analyzed the change of hs-CRP for patients during the follow up.

\section{Statistical analysis}

SPSS13.0 software was used to analyze the data. Measurement data were showed as mean \pm standard deviation $(\bar{x} \pm s)$. Comparison between groups was made by $\mathrm{t}$ test. Enumeration data were analyzed by Chi-square test. There was a significant difference at $P<0.05$. The person-time morbidity and mortality in diabetes group and diabetes combined with hyperlipidemia group were calculated respectively. The differences in the incidence of cardio-cerebrovascular events between the two groups were compared. Multivariable Cox's proportional hazards regression model was used to analyze the factors affecting cardio-cerebrovascular events and to calculate hazard ratio (HR) in each group. Population attributable risk percent (PAR\%) was calculated according to the formula [16], and it was used to analyze the effect of hypertension on cardio-cerebrovascular events in patients with diabetes.

$$
\text { PAR } \%=\text { Morbidity }(\text { HR-1) } /[\text { Morbidity }(\text { HR-1) }+1] \times 100 \%
$$

\section{Result \\ Baseline data}

Three hundred ninety five patients with type 2 diabetes in our hospital were followed up from January 2012 to January 2016, with an average follow-up period of 3.8 years. There were 195 patients in diabetes combined with hyperlipidemia group and 200 patients in diabetes group. There were 28 patients below 45 years old, 102 patients of 45 54 years old, 158 patients of $55 \sim 64$ years old, 77 patients of $65 \sim 74$ years old, and 36 patients over 75 years old, with an average of 58.9 (29 88) years old. Age, SBP, DBP, low-density lipoprotein (LDL), high- 
density lipoprotein (HDL), BMI, total cholesterol, smoking ratio and hs-CRP all were higher in diabetes combined with hyperlipidemia group than in diabetes group, however, FPG was lower $(P<0.05)$ (Table 1$)$.

\section{All-cause mortality and cardio-cerebrovascular events mortality}

All-cause mortality and cardio-cerebrovascular events mortality in diabetes combined with hyperlipidemia group were higher than those in diabetes group during the follow-up. Patients below 65 years old in diabetes combined with hyperlipidemia group had higher allcause mortality and cardio-cerebrovascular events mortality than those in diabetes group $(P<0.05)$. There was no difference in all-cause mortality and cardiocerebrovascular events mortality of patients over 65 years old between the two groups. All-cause mortality and cardio-cerebrovascular events mortality of males and females in diabetes combined with hyperlipidemia group were all higher than those in diabetes group $(P<0.05)$. All-cause mortality and cardio-cerebrovascular events mortality of patients with family history of diabetes in diabetes combined with hyperlipidemia group were all higher than those in diabetes group $(P<0.05)$, and for patients without family history of diabetes there was no difference between the two groups (Table 2).

\section{Incidence of cardio-cerebrovascular events}

Fifty seven of 395 patients suffered from cardiocerebrovascular events. There were 31 patients with myocardial infarction, 18 patients with cerebral infarction and 8 patients with cerebral hemorrhage. The incidence of myocardial infarction, cerebral infarction, cerebral hemorrhage and total cardio-cerebrovascular events in diabetes combined with hyperlipidemia group were all higher than those in diabetes group $(P<0.05)$. Patients below 65 years old in diabetes combined with hyperlipidemia group had higher incidence of myocardial infarction and total cardio-cerebrovascular events than those in diabetes group $(P<0.05)$. The incidence of myocardial infarction and total cardio-cerebrovascular events of females in diabetes combined with hyperlipidemia group were higher than those in diabetes group. The incidence of myocardial infarction, cerebral infarction, cerebral hemorrhage and total cardio-cerebrovascular events of males in diabetes combined with hyperlipidemia group were higher than those in diabetes group $(P<0.05)$ (Table 3).

\section{Multivariable analysis of the effect of hyperlipidemia on cardio-cerebrovascular events in patients with type 2 diabetes}

In this research, the incidence of hyperlipidemia was $44.6 \%$, and the incidence of diabetes combined with hyperlipidemia was $49.4 \%$. Among of them the incidence of hyperlipidemia in patients with all-cause death, cardio-cerebrovascular events death, myocardial infarction, cerebral infarction, cerebral hemorrhage and total cardio-cerebrovascular events were $67.5 \%, 73.2 \%, 69.8 \%$, $70.4 \%, 65.8 \%$ and $61.3 \%$, respectively. All-cause death, cardio-cerebrovascular events death, myocardial infarction, cerebral infarction, cerebral hemorrhage and total cardio-cerebrovascular events were used as the dependent variables. Hypertension, age, gender, FPG, smoking, obesity, high cholesterol, low density lipoprotein cholesterol (LDL-C) and high density lipoprotein cholesterol (HDL-C) were used as the independent variables. The differences in age, gender, obesity, hypertension and smoking were corrected. Multivariable Cox's proportional hazards regression model was used to analyze these factors. The results showed that after covariant correction the risk of myocardial infarction and total cardio-cerebrovascular events in diabetes combined with hyperlipidemia group were 1.54 times $(95 \% C I$ (confidence interval) $1.13-2.07)$ and 1.68 times (95\%CI $1.23-2.24)$ higher than those in diabetes group $(P<0.05)$. PAR\% of hyperlipidemia on all-cause death and total cardio-cerebrovascular events in patients with type 2

Table 1 Baseline data $(\bar{x} \pm s)$

\begin{tabular}{|c|c|c|c|c|c|}
\hline Group & Patients & Age (years) & $\mathrm{DBP}(\mathrm{mmHg})$ & $\mathrm{SBP}(\mathrm{mmHg})$ & BMI $\left(\mathrm{kg} / \mathrm{m}^{2}\right)$ \\
\hline Diabetes & 200 & $52 \pm 0.25$ & $75 \pm 13$ & $120 \pm 14.5$ & $24.8 \pm 0.5$ \\
\hline Diabetes combined with hyperlipidemia & 195 & $58 \pm 0.18^{a}$ & $98 \pm 9^{a}$ & $149 \pm 13.5^{\mathrm{a}}$ & $26.9 \pm 0.8^{a}$ \\
\hline Group & Total cholesterol (mmol/L) & $\mathrm{HDL}(\mathrm{mmol} / \mathrm{L})$ & & LDL (mmol/L) & Smoking (\%) \\
\hline Diabetes & $5.2 \pm 0.89$ & $1.75 \pm 0.18$ & & $1.36 \pm 0.12$ & $23.8 \%$ \\
\hline Diabetes combined with hyperlipidemia & $5.9 \pm 0.67^{\mathrm{a}}$ & $2.68 \pm 0.38^{\mathrm{a}}$ & & $2.45 \pm 0.36^{\mathrm{a}}$ & $38.5 \%^{\mathrm{a}}$ \\
\hline Group & $\mathrm{FPG}(\mathrm{mmol} / \mathrm{L})$ & Hypertension (\%) & Obesity (\%) & Follow-up period (year) & hs-CRP (mg/L) \\
\hline Diabetes & $9.45 \pm 0.16$ & 21.8 & 19.8 & $4.0(3.8-4.2)$ & $1.86 \pm 0.45$ \\
\hline Diabetes combined with hyperlipidemia & $9.04 \pm 0.38^{\mathrm{a}}$ & $35.9^{\mathrm{a}}$ & $29.7^{\mathrm{a}}$ & $4.2(3.7-4.4)^{\mathrm{a}}$ & $9.65 \pm 0.82^{\mathrm{a}}$ \\
\hline
\end{tabular}

Note: $D B P$ diastolic blood pressure, SBP systolic blood pressure, $B M I$ body mass index, $H D L$ high-density lipoprotein, $L D L$ low-density lipoprotein, $F P G$ fasting plasma glucose, $h s$-CRP hyper-sensitive $C$-reactive protein ${ }^{\mathrm{a}} \mathrm{P}<0.05$ 
Table 2 All-cause mortality and cardio-cerebrovascular events mortality (/1000 persons/year)

\begin{tabular}{|c|c|c|c|c|c|}
\hline Patients & Group & All-cause death & Mortality $(95 \% \mathrm{Cl})$ & Cardio-cerebrovascular events death & Mortality $(95 \% \mathrm{Cl})$ \\
\hline \multirow[t]{2}{*}{ Total } & Diabetes & 18 & $4.5(3.67-5.98)$ & 5 & $1.3(0.98-1.65)$ \\
\hline & $\begin{array}{l}\text { Diabetes combined } \\
\text { with hyperlipidemia }\end{array}$ & 32 & $8.4(6.09-9.24)^{a}$ & 14 & $3.7(2.97-4.02)^{\mathrm{a}}$ \\
\hline \multirow[t]{2}{*}{$<65$ years } & Diabetes & 9 & $2.2(1.87-2.48)$ & 3 & $0.6(0.38-0.78)$ \\
\hline & $\begin{array}{l}\text { Diabetes combined } \\
\text { with hyperlipidemia }\end{array}$ & 21 & $5.4(4.81-5.94)^{a}$ & 8 & $1.7(1.42-2.02)^{\mathrm{a}}$ \\
\hline \multirow[t]{2}{*}{$\geq 65$ years } & Diabetes & 26 & $5.2(4.89-5.42)$ & 5 & $0.9(0.88-1.02)$ \\
\hline & $\begin{array}{l}\text { Diabetes combined } \\
\text { with hyperlipidemia }\end{array}$ & 23 & $5.4(5.11-5.64)$ & 6 & $1.1(0.97-1.12)$ \\
\hline \multirow[t]{2}{*}{ Female } & Diabetes & 5 & $1.1(0.87-1.28)$ & 2 & $0.4(0.28-0.53)$ \\
\hline & $\begin{array}{l}\text { Diabetes combined } \\
\text { with hyperlipidemia }\end{array}$ & 17 & $4.4(4.22-4.74)^{a}$ & 7 & $1.5(1.42-1.62)^{\mathrm{a}}$ \\
\hline \multirow[t]{2}{*}{ Male } & Diabetes & 11 & $3.1(2.87-3.28)$ & 4 & $0.7(0.64-0.83)$ \\
\hline & $\begin{array}{l}\text { Diabetes combined } \\
\text { with hyperlipidemia }\end{array}$ & 25 & $4.9(4.82-5.14)^{\mathrm{a}}$ & 9 & $1.9(1.83-2.02)^{\mathrm{a}}$ \\
\hline \multirow[t]{2}{*}{ Family history } & Diabetes & 10 & $2.8(2.57-2.98)$ & 6 & $0.6(0.58-0.73)$ \\
\hline & $\begin{array}{l}\text { Diabetes combined } \\
\text { with hyperlipidemia }\end{array}$ & 25 & $5.9(5.53-6.14)^{a}$ & 12 & $1.9(1.83-2.02)^{a}$ \\
\hline \multirow[t]{2}{*}{ No family history } & Diabetes & 17 & 3.6 (3.37-3.88) & 10 & $1.6(1.48-1.73)$ \\
\hline & $\begin{array}{l}\text { Diabetes combined } \\
\text { with hyperlipidemia }\end{array}$ & 20 & $3.9(3.53-4.14)$ & 12 & $1.9(1.83-2.02)$ \\
\hline
\end{tabular}

$\mathrm{Cl}$ confidence interval

Note: ${ }^{\mathrm{a}} P<0.05$, which is compared with the same patients in diabetes group

diabetes were $9.6 \%$ and $26.8 \%$ (Table 4 ). At the end of the follow-up statistics revealed that the survival rate in diabetes group was significantly higher than that in diabetes combined with hyperlipidemia group (Fig. 1).

\section{Discussion}

Diabetes is a disease caused by multi-source etiology including heredity, social factors, life-style and environment
[17]. The incidence of diabetes is believed to be related to age, family history of diabetes, obesity levels and types, and insulin resistance. However, recent studies have found that cardio-cerebrovascular disease is a major risk factor for the safety of patients with type 2 diabetes, especially for the safety of the elderly. In addition to heredity factor, the pathogenesis of cardio-cerebrovascular disease is more related to the lifestyle and dietary pattern of patients. It is

Table 3 Incidence of cardio-cerebrovascular events (/1000 persons/year) (95\%Cl)

\begin{tabular}{|c|c|c|c|c|c|}
\hline Patients & Group & Total cardio-cerebrovascular events & Myocardial infarction & Cerebral infarction & Cerebral hemorrhage \\
\hline \multirow[t]{2}{*}{ Total } & Diabetes & $3.5(3.37-3.78)$ & $2.3(2.17-2.88)$ & $1.5(1.37-1.78)$ & $0.8(0.66-0.98)$ \\
\hline & $\begin{array}{l}\text { Diabetes combined } \\
\text { with hyperlipidemia }\end{array}$ & $6.4(6.09-7.04)^{a}$ & $4.4(4.11-4.91)^{\mathrm{a}}$ & $3.4(3.24-3.81)^{\mathrm{a}}$ & $1.6(1.42-1.81)^{\mathrm{a}}$ \\
\hline \multirow[t]{2}{*}{$<65$ years } & Diabetes & $3.6(3.57-4.18)$ & $2.5(2.37-2.78)$ & $1.8(1.68-1.96)$ & $0.7(0.6-0.78)$ \\
\hline & $\begin{array}{l}\text { Diabetes combined } \\
\text { with hyperlipidemia }\end{array}$ & $5.2(5.01-5.5)^{\mathrm{a}}$ & $4.1(3.8-4.21)^{\mathrm{a}}$ & $1.7(1.64-1.81)$ & $0.6(0.45-0.81)$ \\
\hline \multirow[t]{2}{*}{$\geq 65$ years } & Diabetes & $2.6(2.47-2.88)$ & $1.8(1.67-1.94)$ & $1.2(1.08-1.36)$ & $0.6(0.57-0.78)$ \\
\hline & $\begin{array}{l}\text { Diabetes combined } \\
\text { with hyperlipidemia }\end{array}$ & $2.8(2.71-2.91)$ & $1.7(1.66-2.01)$ & $1.3(1.24-1.41)$ & $0.5(0.45-0.65)$ \\
\hline \multirow[t]{2}{*}{ Females } & Diabetes & $2.5(2.37-2.75)$ & $1.9(1.78-2.04)$ & $1.1(1.01-1.26)$ & $0.5(0.38-0.61)$ \\
\hline & $\begin{array}{l}\text { Diabetes combined } \\
\text { with hyperlipidemia }\end{array}$ & $4.1(4.01-4.2)^{\mathrm{a}}$ & $3.1(2.8-3.21)^{\mathrm{a}}$ & $1.2(1.04-1.31)$ & $0.6(0.55-0.71)$ \\
\hline \multirow[t]{2}{*}{ Males } & Diabetes & $3.2(3.13-3.4)$ & $2.5(2.31-2.65)$ & $1.7(1.57-1.88)$ & $0.9(0.76-1.08)$ \\
\hline & $\begin{array}{l}\text { Diabetes combined } \\
\text { with hyperlipidemia }\end{array}$ & $6.1(5.89-6.44)^{\mathrm{a}}$ & $4.8(4.61-5.2)^{\mathrm{a}}$ & $2.8(2.74-3.01)^{\mathrm{a}}$ & $1.4(1.22-1.61)^{\mathrm{a}}$ \\
\hline
\end{tabular}


Table 4 Multivariable analysis of the effect of hyperlipidemia on cardio-cerebrovascular events in patients with type 2 diabetes

\begin{tabular}{lllll}
\hline Events & HR $(95 \% \mathrm{Cl})$ & $P$ & Hyperlipidemia morbidity (\%) & PAR (\%) \\
\hline All-cause death & $1.21(0.89-1.31)$ & $>0.05$ & 67.5 & 9.6 \\
Cardio-cerebrovascular death & $1.33(0.97-1.42)$ & $>0.05$ & 73.2 & 20.2 \\
Myocardial infarction & $1.41(1.12-1.56)$ & $<0.05$ & 69.8 & 22.1 \\
Cerebral infarction & $1.32(1.09-1.47)$ & $>0.05$ & 70.4 & 25.7 \\
Cerebral hemorrhage & $0.98(0.78-1.12)$ & $>0.05$ & 65.8 & 28.3 \\
Total cardio-cerebrovascular events & $1.78(1.65-1.98)$ & $<0.05$ & 61.3 & 26.8 \\
\hline
\end{tabular}

PAR\% Population attributable risk percent, $\mathrm{Cl}$ confidence interval

Note: Correction factors are age, gender, obesity, hypertension and smoking

reported that about $75 \%$ of diabetes patients die from cardio-cerebrovascular disease every year [18]. The study found that due to biological regulation dysfunction of insulin, diabetes patients commonly accompanied by lipid metabolism disorder and were complicated by hyperlipidemia [19]. Diabetes combined with hyperlipidemia could accelerate the progress of atherosclerosis and increase the incidence of cardiovascular disease [20]. Hyperlipidemia combined with abnormal hs-CRP may also be a key factor in promoting vascular endothelial injury of patients with hypertension and the incidence of cardiovascular disease. There is growing evidence that low level of CRP is closely related to the risk factor of cardiovascular disease, such as hypertension and hyperlipidemia, and that the elevation of CRP level can increase the incidence of heart disease and stroke for patients with hypertension. And therefore CRP is a proinflammatory factor related to the occurrence and development of atherosclerosis. During the formation of atherosclerotic plaque CRP, complement complexes and foam cells deposited on arterial wall. CRP can be combined with lipoprotein to activate complement system, producing a large number of inflammatory mediators, releasing oxygen free radicals, causing endangium injury, vasospasm and unstable plaque rupture, aggravating the luminal stenosis caused by atherosclerosis and promoting the occurrence of myocardial infarction [21]. In our research, DBP, SBP, HDL, LDL, BMI and hs-CRP in diabetes

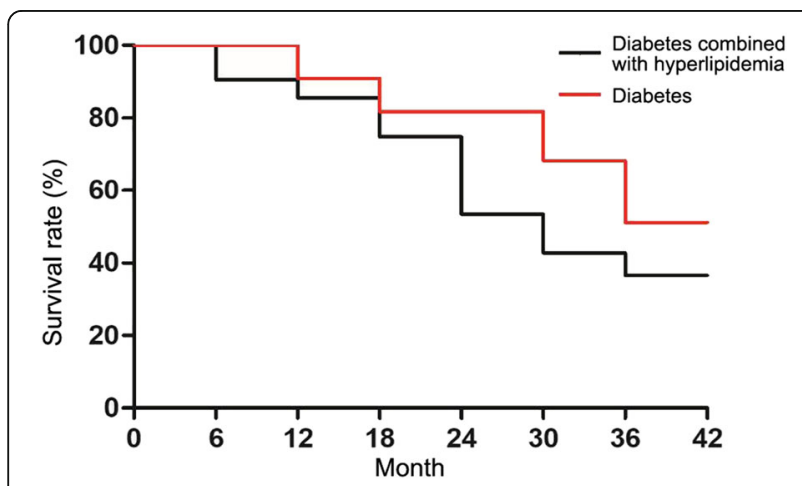

Fig. 1 Survival rate in diabetes group and diabetes combined with hyperlipidemia group at the end of the follow-up combined with hyperlipidemia group were all higher than those in diabetes group. All-cause mortality, cardiocerebrovascular diseases mortality, and the incidence of myocardial infarction, cerebral infarction, cerebral hemorrhage and total cardiovascular events were significantly higher in diabetes combined with hyperlipidemia group than in diabetes group $(P<0.05)$. The results of multivariable Cox's proportional hazards regression model showed that the risk of myocardial infarction and total cardio-cerebrovascular events in diabetes combined with hyperlipidemia group were 1.54 times (95\%CI 1.13-2.07) and 1.68 times (95\%CI 1.23-2.24) higher than those in diabetes group. This result might be caused by lipid metabolism disorder. Lipid metabolism disorder, as a common complication of type 2 diabetes, easily caused angiosclerosis, inducing cardio-cerebrovascular disease like coronary heart disease and cerebral infarction. Overhigh LDL-C level in blood could lead to the accumulation of LDL-C in the coronary artery, which prompted the formation of atheromatous plaque to obstruct the lumen, causing ischemia and hypoxia of myocardium [22, 23]. Hyperlipidemia could damage the vascular endothelial cells, increasing the permeability of vascular wall. Thus the plasma lipoprotein penetrating the inner membrane induced the elimination of macrophages, the proliferation of the smooth muscle cells, atherosclerosis, even prompting the formation of atheromatous plaque and angiostenosis. Therefore, the reduction of blood lipid levels played an effective prevention function on cardio-cerebrovascular disease [24]. The study also proved that lipid metabolism disorder was positively correlated with the incidence of ischemic cardio-vascular disease [25]. Hypercholesterolemia is one of the most important risk factors for atherosclerotic cardiovascular disease (coronary heart disease and ischemic stroke), and coronary heart disease is one of the leading causes of death in diabetics [26,27]. Some studies have revealed that the risk of hypertension and diabetes is growing at a different rate, and that the risk of hypertension and diabetes is increased after 25 months and 27 months of follow-up. Hypertension is a common risk factor of cardiovascular disease, and rational treatment and scientific management can reduce its incidence [28- 
30]. Some studies found that the increased risk of coronary artery disease in diabetics might be partly attributable to diabetes-related lipoprotein abnormalities. Several II level prevention trials including diabetic patients, have demonstrated the effectiveness of lower LDL-C in preventing coronary artery disease deaths. In patients with type 2 diabetes, although the blood lipids value improved, lipid metabolism disorder persisted even if the blood glucose was controlled in the optimal range [31-33]. In this research, all-cause mortality and cardio-cerebrovascular events mortality of patients with family history of diabetes in diabetes combined with hyperlipidemia group were all higher than those in diabetes group, and for patients without family history of diabetes there was no difference between the two groups. The results of family history of diabetes showed the risk of cardiovascular disease increased even though these patients did not have symptoms of early diabetes or diabetes. The symptoms of early diabetes were the further manifestation of early atherosclerosis. The synergistic effect of systemic inflammation and high concentration of blood sugar could damage the function of vascular endothelial cells and induce atherosclerosis lesion. Therefore the effective blood lipid control in early diabetes or in patients with family history of diabetes could reduce the incidence of cardiovascular disease [34].

\section{Conclusions}

Hyperlipidemia increases the risk of cardio-cerebrovascular disease in patients with type 2 diabetes, and hyperlipidemia combined with the elevation of hs-CRP may induce higher risk of cardio-cerebrovascular disease in patients with type 2 diabetes. Medical staffs should take preventive measures according to individual situation to reduce or delay the risk and the onset time of cardiovascular disease in patients with diabetes.

\section{Abbreviations \\ BMI: Body mass index; Cl: Confidence interval; DBP: Diastolic blood pressure; FPG: Fasting plasma glucose; HDL: High-density lipoprotein; HDL-C: High density lipoprotein cholesterol; HR: Hazard ratio; hs-CRP: hyper-sensitive C-reactive pro- tein; LDL: Low-density lipoprotein; LDL-C: Low density lipoprotein cholesterol; PAR\%: Population attributable risk percent; SBP: Systolic blood pressure}

\section{Acknowledgements}

Not applicable.

\section{Funding}

This research was supported by the National Natural Science Foundation of China (grant number: 81570746).

\section{Availability of data and materials}

All data generated or analyzed during this study are included in this published article.

\section{Authors' contributions}

DF contributed to the design and concept of this study, and revised the manuscript critically for important intellectual content. ZL analyzed and interpreted the patient data, and revised the manuscript critically for important intellectual content. YZ analyzed and interpreted the patient data, and drafted the manuscript. XM acquired the data, and drafted the manuscript. LW acquired the data, and drafted the manuscript. GQ contributed to the design and concept of this study, and revised the manuscript critically for important intellectual content. All authors read and approved the final manuscript.

\section{Ethics approval and consent to participate}

This study has been approved by the Ethics Committee of the First Affiliated Hospital of Zhengzhou University, and all participants of the study signed the informed consent.

\section{Consent for publication}

Not applicable.

\section{Competing interests}

The authors declare that they have no competing interests.

\section{Publisher's Note}

Springer Nature remains neutral with regard to jurisdictional claims in published maps and institutional affiliations.

\section{Author details}

${ }^{1}$ Division of Endocrinology Department of Internal Medicine, The First Affiliated Hospital of Zhengzhou University, Zhengzhou, Henan, China. ${ }^{2}$ Ophthalmologic Center, The First Affiliated Hospital of Zhengzhou University, Zhengzhou, Henan, China.

Received: 22 December 2017 Accepted: 7 February 2018

Published online: 08 May 2018

\section{References}

1. International Diabetes Federation. IDF Diabetes Atlas Sixth edition poster update 2014. 2014. http://www.doc88.com/p-7394581233404.html.

2. Sun B, Cheng X, LC M, Tian H, Cl L. Relationship between metabolic diseases and all-cause and cardiovascular disease death in elderly male diabetics during a 10-year follow-up. Nat Med J China. 2014;94:591-5.

3. Chang $C H$, Shau WY, Jiang YD, Li HY, Chang TJ, Sheu WH, et al. Type 2 diabetes prevalence and incidence among adults in Taiwan during 1999-2004: a national health insurance data set study. Diabet Med. 2010;27:636-43.

4. Sh L, Jh T, Zhang W, Ly L, Qz X. Observation on the treatment of mixed hyperlipidemia with simvastatin and Fenofibrate together. Med Inf. 2010;23:3116-7.

5. Lin PJ, Kent DM, Winn A, Cohen JT, Neumann PJ. Multiple chronic conditions in type 2 diabetes mellitus: prevalence and consequences. Am J Manag Care. 2015;21:e23-34.

6. Crawford AG, Cote C, Couto J, Daskiran M, Gunnarsson C, Haas K, et al. Prevalence of obesity, type II diabetes mellitus, hyperlipidemia, and hypertension in the United States: findings from the GE centricity electronic medical record database. Popul Health Manag. 2010;13:151-61.

7. Tadic M, Cuspidi C. Type 2 diabetes mellitus and atrial fibrillation: from mechanisms to clinical practice. Arch Cardiovasc Dis. 2015;108:269-76.

8. Ritzenthaler T, Derex L, Davenas C, Bnouhanna W, Farghali A, Mechtouff L, et al. Safety of early initiation of rivaroxaban or dabigatran after thrombolysis in acute ischemic stroke. Rev Neurol (Paris). 2015;171:613.

9. Wang $C H$, Zhou J, Wang $L X$, Wang L, Li CL, Li HJ. Relationships between risk factors of cardiovascular disease and hyper-sensitive C-reactive protein in elderly patients. People's Mil Surg. 2016;2:161-3.

10. American Diabetes Association. Diagnosis and classification of diabetes mellitus. Diabetes Care. 2012;35(Suppl 1):S64-71. https:/doi.org/10.2337/dc12-s064.

11. Revision Committee of Hypertension Prevention and Cure Guideline of China. Hypertension prevention and cure guideline of China (2010). Chinese J Hypertens. 2011;19:701-43.

12. Revision Committee of Dyslipidemia Prevention and Cure Guideline in Chinese Adults. Dyslipidemia prevention and cure guideline in Chinese adults. Chinese J Cardiol. 2007;35:390-409.

13. Chinese Society of Cardiology of Chinese Medical Association, Editorial Board of Chinese Journal of Cardiology, Editorial Board of Chinese Circulation Journal. Diagnosis and management of acute myocardial infarction. Chinese J Cardiol. 2010;38:675-88.

14. European Heart Rhythm Association, Heart Rhythm Society, Fuster V, Rydén LE, Cannom DS, Crijns HJ, et al. ACC/AHA/ESC 2006 guidelines for the management of patients with atrial fibrillation-executive summary: a report 
of the American College of Cardiology/American Heart Association task force on practice guidelines and the European Society of Cardiology Committee for practice guidelines (writing committee to revise the 2001 guidelines for the Management of Patients with Atrial Fibrillation). J Am Coll Cardiol. 2006;48:854-906.

15. RAO ML. Cerebrovascular disease prevention and cure guideline of China. Beijing: People's Medical Publishing House; 2007.

16. Pasala SK, Rao AA, Sridhar GR. Built environment and diabetes. Int J Diabetes Dev Ctries. 2010;30:63-8.

17. Lin CC, Li Cl, Hsiao CY, Liu CS, Yang SY, Lee CC, et al. Time trend analysis of the prevalence and incidence of diagnosed type 2 diabetes among adults in Taiwan from 2000 to 2007: a population-based study. BMC Public Health. 2013;9:318.

18. CHEN XT. Study on the effect of hypertension and diabetes for elderly with cardiovascular disease. Mod Prev Med. 2011:38:3253-4.

19. Xin W. The effect of arterial stiffness index for Xuzhikang capsule in patients with type 2 diabetes. Chinese J Mod Drug Appl. 2015;9:127-8.

20. Barzilay Jl, Spiekerman CF, Kuller LH, Burke GL, Bittner V, Gottdiener JS, et al. Prevalence of clinical and isolated subclinical cardiovascular disease in older adults with glucose disorders: the cardiovascular health study. Diabetes Care. 2001;24:1233-9. https://doi.org/10.2337/diacare.24.7.1233.

21. Ajmal MR, Yaccha M, Malik MA, Rabbani MU, Ahmad I, Isalm N, et al. Prevalence of nonalcoholic fatty liver disease (NAFLD) in patients of cardiovascular diseases and its association with hs-CRP and TNF-a. Indian Heart J. 2014;66:574-9.

22. HU DY. Chinese expert consensus on clinical application of selective cholesterol absorption inhibitors (2015). Chinese J Cardiol. 2015;5:394-8.

23. Chen GY, Li L, Dai F, Li XJ, Xu XX, Fan JG. Prevalence of and risk factors for type 2 diabetes mellitus in hyperlipidemia in China. Med Sci Monit. 2015;21: 2476-84. https://doi.org/10.12659/MSM.894246.

24. Kabinejadian F, Cui F, Zhang Z, Ho P, Leo HL. A novel carotid covered stent design: in vitro evaluation of performance and influence on the blood flow regime at the carotid artery bifurcation. Ann Biomed Eng. 2013;41:1990-2002.

25. Ma RC, Lin X, Jia W. Causes of type 2 diabetes in China. Lancet Diabetes Endocrinol. 2014;2:980-91.

26. Matsunaga M, Yatsuya $\mathrm{H}$, Iso H, Yamashita $\mathrm{K}$, Li Y, Yamagishi $\mathrm{K}$, et al. Similarities and differences between coronary heart disease and stroke in the associations with cardiovascular risk factors: the Japan collaborative cohort study. Atherosclerosis. 2017;216:124-30.

27. Onat A, Dönmez I, Karadeniz Y, Cakır H, Kaya A. Type-2 diabetes and coronary heart disease: common physiopathology, viewed from autoimmunity. Expert Rev Cardiovasc Ther. 2014;12:667.

28. Wei YH, Jiang JJ, Hu HP. Research on the relationship between microalbuminuria and carotid intima-media thickness in patients with type 2 diabetes mellitus. China J Mod Med. 2007; issue 19. http://en.cnki.com.cn/ Article_en/CJFDTotal-ZXDY200719036.htm.

29. HE YM. Insulin intensive therapy on type 2 diabetes combined with hypertension. China Mod Doctor. 2009:47:43-4.

30. Wang L. Effect of health education of hypertension on chronic disease prevention in community. Mod Diagn Treat. 2014;25:5477-8.

31. Babu A, Kannan C, Mazzone T. Hyperlipidemia and diabetes mellitus. Zhonghua Yu Fang Yi Xue Za Zhi. 2002; https://doi.org/10.1201/ NOE1842141151.ch17.

32. Kujiraoka T, Iwasaki T, Ishihara M, Ito M, Nagano M, Kawaguchi A, et al. Altered distribution of plasma PAF-AH between HDLs and other lipoproteins in hyperlipidemia and diabetes mellitus. J Lipid Res. 2003;44:2006-14.

33. Hu XF, Han XR, Yang ZY, Hu YH, JI T. The impact of broadened diagnostic criteria on the prevalence of hypertension, hyperlipidemia and diabetes mellitus in China. Zhonghua Yu Fang Yi Xue Za Zhi. 2017:51:369-77.

34. Ciccone MM. Endothelial function in pre-diabetes, diabetes and diabetic cardiomyopathy: a review. J Diabetes Metab. 2014;05 https://doi.org/10. 4172/2155-6156.1000364.

\section{Submit your next manuscript to BioMed Central and we will help you at every step:}

- We accept pre-submission inquiries

- Our selector tool helps you to find the most relevant journal

- We provide round the clock customer support

- Convenient online submission

- Thorough peer review

- Inclusion in PubMed and all major indexing services

- Maximum visibility for your research

Submit your manuscript at www.biomedcentral.com/submit
Biomed Central 